\section{Meadow faces GMC over evidence given in child death cases}

\author{
Owen Dyer London
}

The eminent paediatrician Roy Meadow is to face charges of serious professional misconduct from the General Medical Council over his role as a witness for the prosecution in three trials where mothers were wrongly accused of killing their babies.

Alan Williams, a Home Office forensic pathologist who gave evidence in one of those cases, will also be charged with serious professional misconduct by the GMC. Dr Williams's hearing is likely to take place in the summer and that of Professor Meadow in the autumn. The cases will attract immense public interest, after the acquittal of Trupti Patel and the overturning on appeal of murder convictions against Sally Clark and Angela Cannings, all of whom were accused of killing their children.
The government has set up a joint working party, chaired by Helena Kennedy, whose task is to come up with a national protocol for investigating sudden infant deaths.

The Crown Prosecution Service is to review 50 convictions in which Dr Williams gave evidence for the prosecution, stretching back seven years. The service is expected to decide in the next few weeks whether cases involving Professor Meadow will also be reviewed.

Professor Meadow's dictum that "one infant death is a tragedy, two is suspicious, and three is murder" became known as Meadow's law. Trupti Patel lost three babies. Sally Clark lost two. Angela Cannings lost three, but was accused of killing two.

The complaint against $\mathrm{Dr}$
Williams was lodged with the GMC by Sally Clark's former MP, Martin Bell. It is not known who lodged the complaint against Professor Meadow, but most criticism of his role has also centred on the Clark case. Sally Clark was convicted in 1999 of smothering her two infants.

Professor Meadow told the jury that the chance of two cot deaths occurring in an affluent family was one in 73 million.

When Ms Clark's conviction was overturned the Court of Appeal described Professor Meadow's evidence as "grossly misleading." It was also found on appeal of the case that Dr Williams had withheld evidence of Staphylococcus aureus infection in the cerebrospinal fluid of Harry Clark, the second of Sally Clark's babies to die.

Neither Dr Williams nor Professor Meadow are commenting on the GMC case, but Alan Craft, president of the Royal College of Paediatrics and Child Health, spoke to the $B M J$ about Professor Meadow, who is himself a former president of the college.

Professor Craft said: "I'm glad the case will come before the GMC, and I'm sure Roy is too. It will be his first chance to publicly answer the criticisms that have been levelled against him. This whole furore about his statistical evidence is misleading, because he was asked about the chances of two children dying from sudden infant death syndrome [SIDS], when it was already established in the Clark case that neither the prosecution nor the defence claimed SIDS as the cause of death. Roy gave the right answer to the wrong question."

In a paper published in the $B M J$ (2002;324:41) following the failure of Clark's first appeal, Professor Meadow said that the figure of one in 73 million he cited in court was taken from the report by Peter Fleming, Sudden Unexpected Deaths in Infancy (London: Stationery Office, 2000), which was carried out as part of the Department of Health's Confidential Enquiry into Stillbirths and Deaths in Infancy.

\section{Italy to pass new law on assisted reproduction}

Fabio Turone Milan

Italy's Senate has passed a law on assisted reproduction that makes it a crime to freeze or destroy human embryos or to use donated sperm and eggs.

The new rules-which will need an additional, formal approval by the lower house but are expected to come into effect in early 2004-limit the number of oocytes that can be fertilised to three. They also state that all the embryos created must be transferred into the woman's womb.

Additionally they restrict the use of assisted reproduction techniques to sterile heterosexual couples in a stable relationship and ban all forms of pre-implantation genetic testing.

Antonio Lanzone, head of the centre for assisted reproduction at the Catholic University, Rome, said, "The principle of safeguarding the embryo from fertilisation, which I subscribe to, is the main goal of this law, which pays a price in terms of loss of efficiency and increase of risks."
However, Arne Sunde, chairman of the European Society of Human Reproduction and Embryology, said it was a "disaster for women" and expressed his fear of consequences all around Europe.

Most Italian experts on assisted reproduction agree with Professor Sunde. Luca Gianaroli, scientific director of the Italian Society for the Study of Reproductive Medicine, Bologna, said the law was in sharp contrast to the guidelines of the World Health Organization. He said, "According to an analysis we conducted on the medical charts of 100 successful pregnancies, fertilising just three oocytes will cut which explicitly protects the health of its citizens.

"We expect a strong mobilisation to call for a referendum to repeal the law," predicts Giovanni Monni, a member of the board of the European Association of Perinatal Medicine and a specialist in genetic testing in Cagliari, Sardinia. "Around 13\% of Sardinians carry the gene for thalassaemia. We have performed around 40 pre-implantation genetic tests so far, and we were planning to perform 300 in 2004. Our previous experience of 6500 prenatal tests for thalassaemia tells us that out of the 1600 fetuses found to be ill, all except 20 were aborted."

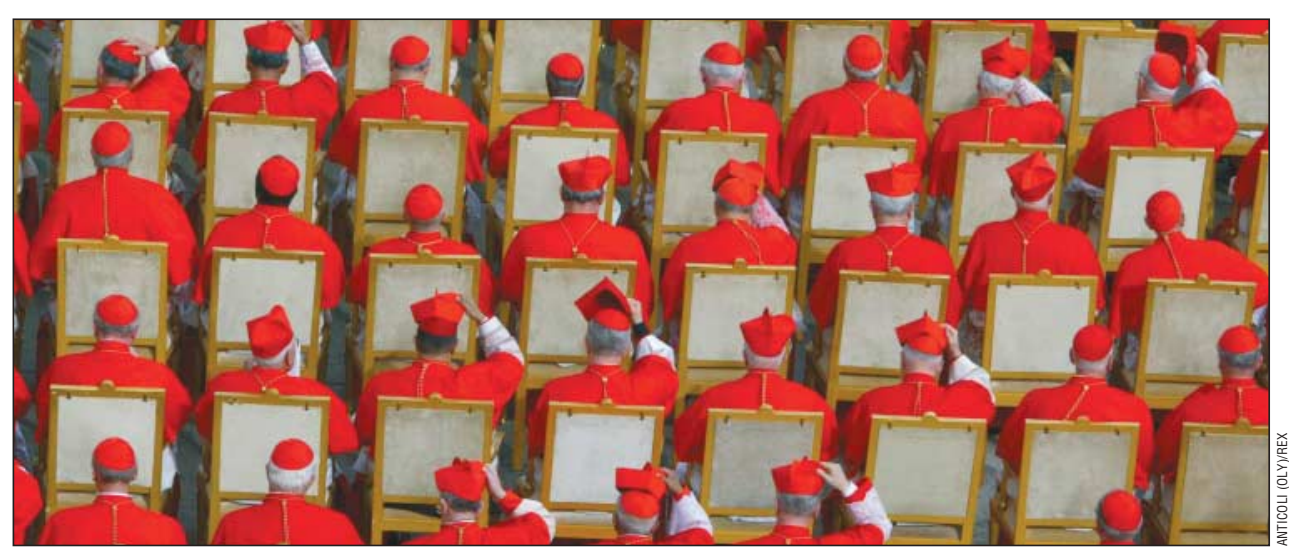

Papal power: some Catholics in Italy's opposition party sided with the centre-right government 